\title{
Optimization of solid-liquid extraction of polar substances from pitaya peel flour
}

\author{
Moises Oliveira Lara ${ }^{1} \oplus$, Daryne Lu Maldonado Gomes da Costa $^{1} \oplus$, Elaine Arruda Oliveira Coringa ${ }^{1}[0$ \\ ${ }^{1}$ Instituto Federal de Ciência e Tecnologia de Mato Grosso, Campus Bela Vista, Cuiabá, MT, Brasil. E-mail: moises-lara@hotmail.com; daryne.costa@blviffmt.edu.br; \\ elaine.coringa@blv.ifmt.edu.br
}

ABSTRACT: Pitaya, or dragon fruit, (Hylocereus polyrhizus) contains in its pulp and peel a high concentration of phenolic compounds, flavonoids and high antioxidant activity. The pulp is used in industries and the peel can be a source of bioactive compounds. The aim of this study was to optimize the extraction of phenolic compounds from pitaya peel flour, dried through freeze-drying. Thus, a central composite rotatable design (CCRD) was performed with two variables $\left(X_{1}=\right.$ ethanol percentage, of $0-100 \%$ as extraction solvent; $X_{2}=$ extraction time, of $5-120$ minutes assisted by ultrasound) resulting in 11 experiments. The response variables were the content of total phenolic compounds by the methods of Folin-Ciocalteau and Fast Blue BB, total flavonoids and antioxidant activity by capture of radicals 2,2'-azino-bis(3-ethylbenzothiazoline-6-sulfonic acid); 2,2- diphenyl1-picrylhydrazyl (DPPH); reduction of iron III (FRAP). It was possible to design the response surface for the analysis of total flavonoids and ABTS. The region of optimal flavonoids extraction, where the extract also demonstrated greater antioxidant activity by the ABTS method, is comprised between 13 and $57 \%$ of the ethanol as a solvent and time above 86 minutes of extraction in ultrasonic bath.

Key words: freeze-drying; Hylocereus polyrhizus; phenolic compounds; residue

\section{Otimização da extração solido-liquido de substâncias polares}

\section{da farinha da casca da pitaya}

RESUMO: A pitaya (Hylocereus polyrhizus) contém em sua polpa e casca elevada concentração de compostos fenólicos, flavonoides e alta atividade antioxidante. A polpa tem aplicação nas indústrias e a casca pode ser fonte de compostos bioativos de interesse. 0 objetivo deste trabalho foi otimizar a extração de compostos fenólicos da farinha da casca da pitaya seca por liofilização. Dessa forma foi realizado um delineamento composto central rotacional (DCCR) com duas variáveis $\left(X_{1}=\right.$ percentual de etanol, de $0-100 \%$ como solvente de extração; $X_{2}=$ tempo de extração, de $5-120$ minutos assistida por ultrassom) resultando em 11 experimentos. As respostas analisadas foram o teor de compostos fenólicos totais pelos métodos de Folin - Ciocalteau e Fast Blue BB, flavonoides totais e atividade antioxidante por: captura dos radicais 2,2 - Azinobis (3etilbenzo - tiazolina - 6 - ácido sulfurico) (ABTS); 2,2 - difenil - 1 - picril - hidrazil (DPPH); redução do ferro III (FRAP). Foi possível a construção da superfície de resposta para as análises de flavonoides totais e ABTS. A região de extração ótima de flavonoides, onde o extrato também apresenta maior atividade antioxidante pelo método ABTS, está compreendido entre $13 \mathrm{e}$ $57 \%$ de etanol como solvente e tempo acima de 86 minutos de extração em banho ultrassônico.

Palavras-chave: liofilização; Hylocereus polyrhizus; compostos fenólicos; resíduo 


\section{Introduction}

Food sources like fruits and vegetables are rich in antioxidants that have benefits for the human health. Phenolic compounds have demonstrated antioxidant action and potential anticarcinogenic and protective effects against cardiovascular diseases (Duthie et al., 2000). Such benefits are attributed to the sequestration of free radicals and metal chelators, reducing the action of reactive-oxygen species (Ozkan et al., 2016).

Fruit consumption is associated with a better life quality due to their high content of vitamins, minerals and antioxidants. Standing out among these fruits are the exotic ones, with atypical shapes and unique flavors, which can be rich in functional compounds, and attract the attention of consumers (Rodrigues et al., 2018).

Pitaya has a high concentration of bioactive compounds (phenolic and antioxidants) in its pulp and peel, granting it characteristics with antioxidant potential, as well as antiinflammatory and chemo-preservative activities (Hua et al., 2016).

In countries such as Malaysia, Taiwan, Vietnam and Thailand, pitaya is grown on a large scale. The pulp of this fruit is mostly used in the food industry for the production of beverages, ice cream, jellies and sweets; its peel does not have a specific application despite having high concentrations of bioactive compounds, and it is considered an industrial residue even though detains about $20 \%$ of the fruit weight (Alves et al., 2018).

One form of making use of these residues is by extracting their plant matter compounds. This extraction is performed by mixing the residue with a certain solvent capable of removing the compounds of interest. After the extraction, the compounds can then be purified and isolated. However, to that end, it is necessary employing effective extraction methods and define the extraction parameters.

There are several traditional extraction methods, such as the Soxhlet, heat reflux and maceration; however, these techniques present several disadvantages like the low yield and the high cost. In order to circumvent these disadvantages, there are emerging technologies replacing these traditional techniques, such as the following: extraction of high hydrostatic pressure, ultrasonic bath, pulsed electric fields, supercritical fluids and microwaves, where it is possible to increase the mass transfer rates, cellular permeability, diffusion of bioactive compounds and the extraction yield, in addition to reducing the energy consumption, extraction time and the organic solvents usage (Ferreres et al., 2017; Xu et al., 2017; Moreira et al., 2018).

In order to determine the optimal extraction conditions for such compounds in a plant matrix, it is necessary evaluating some extraction parameters like the extraction method and time, the temperature and the solvent used (Xu et al., 2017; Aliakbarlu et al., 2018; Alves et al., 2018; Aware et al., 2018).

With this in mind, the present study aimed to present optimal conditions for extracting polar bioactive compounds, more specifically phenolic compounds, from pitaya peel flour (Hylocereus polyrhizus (Weber) Britton \& Rose) dried by lyophilization (freeze-drying) and to suggest an application of it in the food industry.

\section{Materials and Methods}

Acquisition of the raw material (pitaya peel flour)

The fruits were obtained in May 2018 at the local market in the municipality of Cuiabá-MT, and then transported, at room temperature, in closed polyethylene bags to the foodprocessing laboratory of the Federal Institute of Education, Science and Technology of Mato Grosso - Campus Cuiabá Bela Vista (IFMT - Bela Vista).

After removing the packages, the fruits that were between 190 and 260 grams were selected considering the following: ripe stage of ripeness; violet color; and absence of soft parts on their surface.

Thereafter, the fruits were washed in running water and sanitized by their immersion in chlorinated water $\left(50 \mathrm{mg} \mathrm{L}^{-1}\right.$ of active chlorine), for a period of 15 minutes, followed by rinsing with distilled water.

Subsequently, the fruits were cut longitudinally and their pulp removed with the aid of properly cleaned utensils, thus separated into pulp and peel. The peels were fractionated and packed, in portions of up to 100 grams, inside lowdensity polyethylene bags and frozen in a freezer operating at temperatures of around $-15^{\circ} \mathrm{C}$, sheltered from the light.

Two drying methods were performed on the pitaya peel in order to evaluate the most suitable one for conserving the substances of interest. For that matter, drying was performed in an oven with air circulation and renewal at $45{ }^{\circ} \mathrm{C}$ for 14 hours in an Thoth-brand equipment, and in a freeze-dryer (Liotop - L101) at $-56^{\circ} \mathrm{C}$ for 72 hours.

After drying, the now dry flour samples were ground with the aid of a mortar and pestle and sieved in order to standardize their granulometry. Later, the extractions were performed for evaluating their phenolic compounds content, by the Folin-Ciocalteau method, flavonoids and antioxidant activity by the DPPH method.

\section{Acquisition of the extract from pitaya peel flour}

The extractions occurred with mixing pitaya peel flour with solvent (ethanol), in the proportion of 1:100, with the flour remaining for 20 minutes with the solvent in an ultrasonic bath, with the extract filtered on a quantitative paper filter afterwards.

\section{Design of the phenolic compounds extraction}

Optimizing the extraction of phenolic compounds, flavonoids and antioxidant activity from pitaya peel was through a central composite rotatable design (CCRD) with two independent variables (ethanol concentration in water $\left(X_{1}\right)$; and ultrasound-assisted extraction time $\left(X_{2}\right)$ with the Unique UltraSonic ${ }^{\star}$ equipment). Six responses variable were evaluated (Total Phenolic Compounds by the Folin-Ciocauteau method (TPC-FC); Total Phenolic Compounds by Fast Blue BB 
Table 1. Experimental design for optimizing the phenolic compounds extraction from freeze-dried pitaya peel flour in function of the ethanol concentration and the ultrasoundassisted extraction time.

\begin{tabular}{cccccc}
\hline \multirow{2}{*}{ Treatment } & \multicolumn{2}{c}{ Coded values } & \multicolumn{2}{c}{ Real values } \\
\cline { 2 - 5 } & Ethanol & Time & \% of Ethanol & Time* \\
\hline 1 & -1 & -1 & 14.65 & 18 \\
2 & 1 & -1 & 85.35 & 18 \\
3 & -1 & 1 & 14.65 & 102 \\
4 & 1 & 1 & 85.35 & 102 \\
5 & -1.41 & 0 & 0 & 60 \\
6 & 1.41 & 0 & 100 & 60 \\
7 & 0 & -1.41 & 50 & 5 \\
8 & 0 & 1.41 & 50 & 120 \\
9 & 0 & 0 & 50 & 60 \\
10 & 0 & 0 & 50 & 60 \\
11 & 0 & 0 & 50 & 60 \\
\hline
\end{tabular}

*Value expressed in minutes.

method (TPC-FBBB); Total Flavonoids (TF); and determination of antioxidant activity by DPPH, ABTS and FRAP methods). Thereby, the design, composed of the factorial plus axial and central points, resulted in 11 experiments described in Table 1.

The results obtained in the experiments were fit in a second-order mathematical model (Equation 1) and the effects of the independent variables on the response variables were observed in an analysis of variance.

$$
y=\beta_{0}+\beta_{1} X_{1}+\beta_{2} X_{1}^{2}+\beta_{3} X_{2}+\beta_{4} X_{2}^{2}+\beta_{5} X_{1} X_{2}
$$

in which: $y$ is the response variable, $\beta_{0}$ is the regression coefficient, $\beta_{1}$ is the coefficient for the variable $X_{1}$ (ethanol concentration), $\beta_{3}$ is the coefficient for the variable $x_{2}$ (extraction time assisted by ultrasound) and $\beta_{5}$ is the interaction coefficient between the variables $X_{1}$ and $X_{2}$. $\beta_{2}$ and $\beta_{4}$ are the coefficients from variables $X_{1}^{2}$ and $X_{2}^{2}$.

Quantification of total phenolic compounds by the FolinCiocauteau method (TPC-FC)

The determination of phenolic compounds in the obtained extracts was performed as according to Woisky \& Salatino (1998), where $0.5 \mathrm{~mL}$ of the obtained extract and $2.5 \mathrm{~mL}$ of the Folin-Ciocalteau solution were mixed in test tubes followed by a five-minute rest. After that, $2 \mathrm{~mL}$ of $4 \%$ sodium carbonate were added and then the tubes were homogenized. After resting for two hours, the readings were taken at $740 \mathrm{~nm}$ by the UV-1800 model UV-Visible spectrophotometer from the Shimadzu brand. A blank was performed by replacing the sample with ethanol; the standard curve was obtained with gallic acid standard in concentrations between 0 and $100 \mu \mathrm{g} \mathrm{mL}^{-1}$; and the results were expressed in $\mathrm{mg}$ equivalent in gallic acid (EGA) per $100 \mathrm{~g}$ from the sample of freeze-dried pitaya peel flour on a dry basis.

Quantification of total phenolic compounds by the Fast Blue BB method (FBBB)

The determination of phenolic compounds by the Fast Blue BB method was performed as according to Medina (2011), where $1 \mathrm{~mL}$ of the obtained extract and $0.1 \mathrm{~mL}$ of the Fast Blue BB Salt $0.1 \%$ solution were added in a test tube. After 1 minute of reaction, $0.1 \mathrm{~mL}$ of a $5 \%$ sodium hydroxide was added and the reaction went on for more 90 minutes. Following its ending and the one-minute stirring, the reading was taken by the spectrophotometer at $420 \mathrm{~nm}$. A blank was performed by replacing the sample with ethanol, with the standard curve constructed with gallic acid standard from 5 to $125 \mu \mathrm{g} \mathrm{mL}^{-1}$ and the result expressed in mg EGA per 100 grams from the sample of the freeze-dried pitaya peel flour in dry basis.

\section{Quantification of Total Flavonoids}

The determination of flavonoids was performed as according to a modified methodology of Jurd \& Geissman (1956), where it was added in test tubes $0.5 \mathrm{~mL}$ of the obtained extract, $4.4 \mathrm{~mL}$ of $80 \%$ ethanol, $0.1 \mathrm{~mL}$ of sodium acetate and $0.1 \mathrm{~mL}$ of aluminum nitrate. The blank was prepared by using $0.5 \mathrm{~mL}$ of $80 \%$ ethanol (v:v). After stirring the tubes, the reaction occurred for 40 minutes and the spectrophotometer reading was taken at $415 \mathrm{~nm}$, with the equipment zeroed with the blank. For calculating the result, a standard quercetin curve with concentration ranging from 5 to $60 \mu \mathrm{g} \mathrm{mL}^{-1}$ was constructed, with the result expressed in mg equivalent of quercetin per 100 grams of sample from the freeze-dried pitaya peel flour.

\section{Antioxidant activity determination}

The determinations of antioxidant activity followed the methodology described by Rufino et al. (2010) for DPPH, $A B T S$ and FRAP and the results were presented in a dry-basis sample.

Determination of DPPH occurred with the addition, in test tubes, of $3.9 \mathrm{~mL}$ of the radical DPPH solution and $0.1 \mathrm{~mL}$ of the extract, followed by homogenization and waiting the reaction until stabilization (30 minutes) of its reading on a spectrophotometer at $515 \mathrm{~nm}$. The results were expressed in $\mathrm{EC}_{50}$.

Determination of ABTS occurred with the addition, in test tubes, of $3.0 \mathrm{~mL}$ of the radical ABTS solution and $30 \mu \mathrm{L}$ of the extract, and after 6 minutes the reading was taken on a spectrophotometer at $734 \mathrm{~nm}$. The results were expressed in $\mu \mathrm{M}$ of trolox per gram and, and for that, a standard trolox curve was constructed with concentrations ranging from 100 to $2000 \mu \mathrm{M}$.

Determination of FRAP occurred with the addition, in test tubes, of $90 \mu \mathrm{L}$ of extract, $270 \mu \mathrm{L}$ of distilled water and $2.7 \mathrm{~mL}$ of the FRAP reagent, followed by stirring in a water bath at $37^{\circ} \mathrm{C}$ for 30 minutes and later reading at $595 \mathrm{~nm}$ on a spectrophotometer. The results were expressed in $\mu \mathrm{M}$ of ferrous sulfate per gram of sample, and for that, a standard ferrous sulfate curve was constructed with concentrations from 500 to $2000 \mu \mathrm{M}$.

\section{Statistical analysis}

The Student $t$ test for comparing two means was performed by using the Microsoft Excel program, available 
in the Microsoft Office Home and Student 2016 package. The multiple regression and the analysis of variance (ANOVA) were performed employing the Protimiza Experimental Design program at $5 \%$ significance. Principal component analysis (PCA) and Pearson correlation were performed with the $\mathrm{R}$ program, version 3.5.1.

\section{Results and Discussion}

\section{Choosing the drying method}

From the methods evaluated for the drying of the pitaya peel, the effect for the quantification of phenolic compounds, flavonoids and antioxidant capacity by the DPPH method is observed (Table 2).

As expected, using the freeze-drying technique made it possible to attain better values in the analyzed parameters when comparing to drying in an air-circulation oven. This is due to the freeze-drying method non-exposure to high temperatures, conserving both the characteristics and compounds of the sample. Therefore, this justifies choosing freeze-drying as a drying method for obtaining flour from pitaya peel and conducting the experiment following stages.

As it is already known and the literature demonstrates, considering the evaluated techniques in the present study, using temperature during the food processing promotes sensory and nutritional alterations, such as changes in the taste, color, texture and phenolic content. One form of minimizing the damage caused is reducing the heat rate that the food can be subjected to. Mehta et al. (2019), in a study conducted with tomato juice, concluded that employing the processing with lesser heat use obtained a greater conservation of the bioactive compounds present in the raw material. According to Lang et al. (2019) in a study conducted with the drying of black rice, increasing the temperature reduced the concentration of phenolic compounds, flavonoids and anthocyanins. However, the loss of bioactive compounds by using temperature can vary according to the chemical structure of these very compounds present in the sample. According to Paepe et al. (2014), in a study conducted on apple juice, procyanidin oligomers are highly sensitive to heat while the hydroxycinnamic acids were more resistant to it. The results obtained corroborate with the literature data, since the contents of total phenols and flavonoids were lower and the antiradical antioxidant activity, by DPPH, was lower when using the oven-drying method instead of the freeze-drying.

Optimization of the extraction of phenolic compounds, flavonoids and antioxidants from the pitaya peel flour

Due to the differences in the mechanisms that evaluate the oxidation in analyzes for determining the antioxidant activity (Table 3), three methods were used in the present study. The analysis by DPPH and ABTS evaluate the ability of a substance in sequestering a free radical, based on the reduction of DPPH and $A B T S$, respectively, when the radical hydrogen cession occurs by part of the substrate of interest. The difference between the methods is that, while the ABTS solubilizes in aqueous and alcoholic media, DPPH only solubilizes in an alcoholic medium, which can be limiting when studying the hydrophilic compounds action (Arnao, 2000). On the other hand, the FRAP method measures the antioxidant capacity in terms of the ability in reducing the iron that biological fluids possess (Pulido et al., 2000).

In Table 3 is observed that, for the TPC-FC method, the values varied between 106.47 and 540.96 mg EGA $100 \mathrm{~g}^{-1}$;

Table 2. Comparison of the contents of phenolic compounds, flavonoids and antioxidant capacity in pitaya peel flour by oven drying and freeze-drying.

\begin{tabular}{|c|c|c|c|}
\hline Drying method & 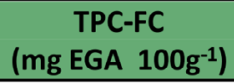 & $\begin{array}{l}\text { Total flavonoids } \\
\left(\mathrm{mg} \text { EQ } 100 \mathrm{~g}^{-1}\right)\end{array}$ & $\begin{array}{c}\text { DPPH } \\
\mathrm{EC}_{50}\left(\mathrm{mg} \cdot \mathrm{kg}^{-1}\right) \\
\end{array}$ \\
\hline Freeze-drying & $88.40^{\mathrm{a}} \pm 6.26$ & $29.27^{a} \pm 1.81$ & $25.42^{b} \pm 0.17$ \\
\hline Oven & $29.44^{b} \pm 1.46$ & $17.76^{b} \pm 1.39$ & $35.75^{a} \pm 0.46$ \\
\hline
\end{tabular}

In which: TPC-FC = Total phenolic compounds by the Folin-Ciocalteau method and DPPH = antioxidant activity by the 2,2-diphenyl-1-picrylhydrazyl radical; EGA = equivalent of gallic acid; $\mathrm{EQ}=$ equivalent of quercetin and $\mathrm{EC}_{50}=$ equivalent to $50 \%$ reduction of the radical. Means followed by the same letter in the columns do not differ from each other by the Student t test at $5 \%$ significance.

Table 3. Results obtained from the central composite rotatable design for total phenolic compounds and total flavonoids.

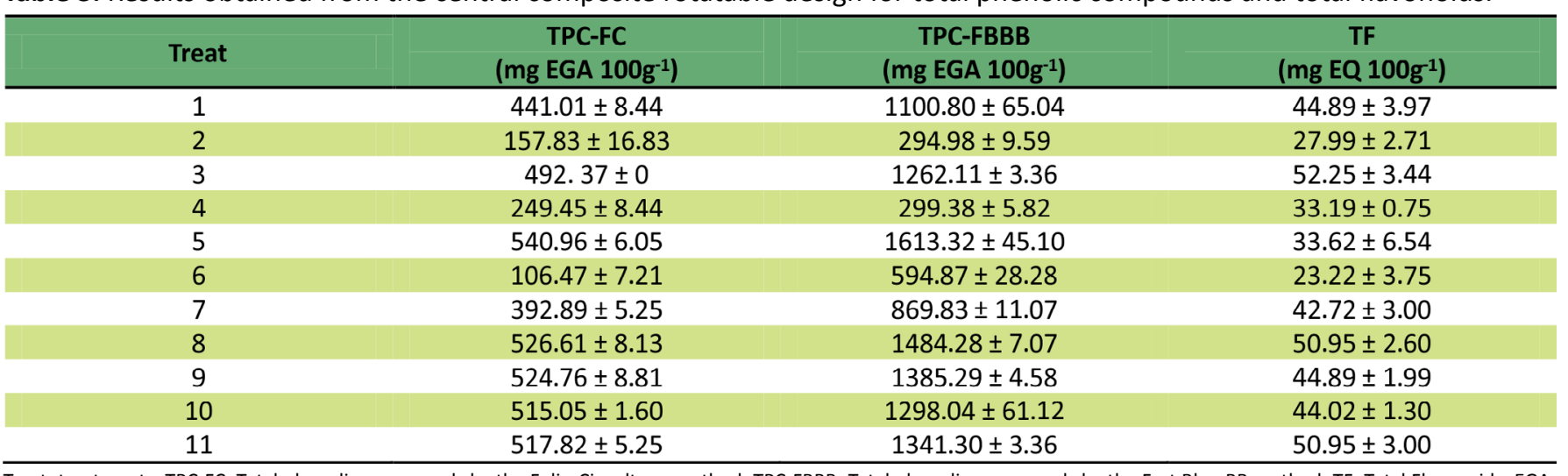

Treat: treatments; TPC-FC: Total phenolic compounds by the Folin-Ciocalteau method; TPC-FBBB: Total phenolic compounds by the Fast Blue BB method; TF: Total Flavonoids; EGA: equivalent to gallic acid; $\mathrm{EQ}$; equivalent to quercetin. Values expressed in dry basis. 
whereas for TPC-FC the variation was between 294.98 and $1613.32 \mathrm{mg}$ EGA $100 \mathrm{~g}^{-1}$; and for the TF it was between 23.22 and $52.25 \mathrm{mg}$ EQ.100 $^{-1}$ (Table 3).

According to Table 4, there is a difference between the values of TPC-FC and TPC-FBBB, when compared, of up to 2.9 times for each treatment. This presented difference was predicted due to the non-specific characteristic of the FolinCiocalteau method to the phenolic compounds, able to react with sodium bisulfites, reducing sugars, ascorbic acid, some transition metals and amino acids such as tryptophan and tyrosine. On the other hand, the Fast Blue BB method reacts directly with the phenolic compound, composing a chemically stable complex (Granato et al., 2016). Therefore, it can be stated that the TPC-FC is a method that underestimates the results, corroborating the data by Medina (2011) and Lester et al. (2012).

No comparisons were found in the literature regarding the TPC-FC and TPC-FBBB methods for freeze-dried pitaya peel; however, several other plant sources were compared and all these studies pointed higher values for the Fast Blue BB test in comparison with the Folin-Ciocalteau test (Medina, 2011; Kang et al., 2012; Lester et al., 2012; Fetni et al., 2017). According to Medina (2011), the TPC-FBBB method quantified concentrations up to 6.6 times higher in beverages and grain samples than the TPC-FC test; Fetni et al. (2017) found concentrations up to 1.7 times higher by the TPC-FBBB method, in a sample of Rosa canina L.; Lester et al. (2012) identified values 2.9 times higher in strawberry samples; and Kang et al. (2012) quantified values of up to 3.4 times higher in an açaí sample.

When comparing the studies on the bioactive compounds from the pitaya peel, a relevant study was conducted by Fathordoobady et al. (2016), who found TPC-FC at a concentration of $139.41 \mathrm{mg}$ EGA $100 \mathrm{~g}^{-1}$ of dry sample, while Wu et al. (2006) obtained flavonoids values at a concentration of $8.33 \mathrm{mg}$ of catechin $100 \mathrm{~g}^{-1}$ dry extract. The antioxidant activity by the DPPH method was observed by Jeronimo (2016), who determined an $\mathrm{EC}_{50}$ of $445.20 \mu \mathrm{g} \mathrm{mL}^{-1}$ in a freezedried peel extract. According to Leong et al. (2019), the result for the FRAP test was of $6.89 \mu \mathrm{M}$ of $\mathrm{Fe}(\mathrm{II}) \mathrm{g}^{-1}$ and, for the ABTS test, the value was of $18.63 \mu \mathrm{M}$ trolox $g^{-1}$ in dry peel extract, demonstrating that according to Tables 3 and 4, FCP has a high concentration of phenolic compounds and a high antioxidant capacity.

The two following conditions must be met for constructing the response surface: for regression/residue, the $F_{\text {table }}$ must be greater than or equal to the $\mathrm{F}_{\text {calculated }}$; for lack of fit/pure error, the $F_{\text {table }}$ must be smaller than or equal to the $F_{\text {calculated }}$ (Rodrigues \& lemma, 2014). Therefore, Table 5 demonstrates that the model fits only for the Flavonoids (TF) and ABTS response variables, which had their effects calculated (Table 5 ).

According to Table 6 , the concentration of ethanol $\left(X_{1}\right)$ as a solvent of polar compounds is significant $(p<0.05)$ for the two response variables, and the ultrasound-assisted extraction time $\left(X_{2}\right)$ did not present significance. It is also possible to observe the coefficients that did not influence the result at the $5 \%$ level, thus the simplified mathematical models for TF and $\mathrm{ABTS}$ are in Equations 2 and 3, respectively.

$$
\begin{gathered}
Y=519.21-142.57 X_{1}-111.89 X_{1}^{2}+41.51 X_{2}-43.78 X_{2}^{2} \\
Y=46.62-6.33 X_{1}-8.61 X_{1}^{2}
\end{gathered}
$$

in which: $X_{1}$ : ethanol percentage and $X_{2}$ : ultrasound-assisted extraction time.

With the construction of the response surfaces (Figure 1 ), it is possible to view the optimal conditions for extracting polar bioactive compounds, having as variables the ethanol concentration used as a solvent and the extraction time in an ultrasonic bath.

Regarding the flavonoids, it is possible to view that the region of high concentration is comprised between 13 and $57 \%$ of ethanol and time above 86 minutes, reaching the maximum values in 120 minutes. Results found for ethanol concentration are in agreement with the literature: according to Cassol et al. (2019), ethanol as a solvent did not have better results for extraction of jatoba flour; Liu et al. (2000) verified that solvents with high or very low polarity are not generally good extractors for bioactive compounds, with the combination of ethanol and water (1:1) more suitable for this; according to Alves et al. (2018), in their study on

Table 4. Results obtained from the central composite rotatable design on the antioxidant activity.

\begin{tabular}{cccc}
\hline Treat & $\begin{array}{c}\text { DPPH } \\
\left(\mathrm{EC}_{50} \mathrm{mg} \mathrm{L}^{-1}\right)\end{array}$ & $\begin{array}{c}\text { ABTS } \\
\left(\mu \mathrm{M} \text { of trolox } \mathbf{~}^{-1}\right)\end{array}$ & $\begin{array}{c}\text { FRAP } \\
\left(\mu \mathrm{M} \text { of ferrous sulfate } \mathrm{g}^{-1}\right)\end{array}$ \\
\hline 1 & $98.59 \pm 0.65$ & $25.71 \pm 0.06$ & $46.79 \pm 0.06$ \\
2 & $372.35 \pm 37.58$ & $6.94 \pm 0.01$ & $20.01 \pm 1.34$ \\
3 & $97.11 \pm 1.29$ & $23.72 \pm 3.92$ & $46.64 \pm 0.63$ \\
4 & $490.60 \pm 1.80$ & $21.49 \pm 0.12$ & $22.15 \pm 0.05$ \\
5 & $48.76 \pm 0.44$ & $30.46 \pm 1.07$ & $70.37 \pm 0.23$ \\
7 & $269.88 \pm 20.15$ & $5.67 \pm 0.02$ & $46.08 \pm 0.13$ \\
8 & $96.35 \pm 2.87$ & $25.35 \pm 0.21$ & $70.76 \pm 0.22$ \\
10 & $48.36 \pm 0.43$ & $39.68 \pm 3.92$ & $70.70 \pm 0.04$ \\
11 & $47.90 \pm 0.89$ & $37.03 \pm 0.38$ & $69.93 \pm 0.13$ \\
\hline
\end{tabular}

Treat: treatments; DPPH: antioxidant activity by the 2,2-diphenyl-1-picrylhydrazyl radical; ABTS: antioxidant activity by the 2,2'-azino-bis(3-ethylbenzothiazoline-6-sulfonic acid) radical; FRAP: antioxidant activity in reducing the Fe(III) by the TPTZ complex (2,4,6-Tris(2-pyridyl)-s-triazine). Values expressed in dry basis. 
Table 5. Analysis of variance of the data obtained in the experiment to determine the TPC-FC, TPC-FBBB, antioxidant activity by DPPH, FRAP and ABTS.

\begin{tabular}{|c|c|c|c|c|c|}
\hline SV & S.Q. & D.o.F. & M.S. & Fcalc & $\mathrm{p}$-Value \\
\hline \multicolumn{6}{|c|}{ TPC-FC } \\
\hline Regression & 248246.29 & 5 & 49649.25 & 32.27 & $0.00082^{*}$ \\
\hline Residues & 7691.68 & 5 & 1538.33 & & \\
\hline Lack of fit & 7641.58 & 3 & 2547.19 & 101.68 & 0.00975 \\
\hline Pure Error & 50.10 & 2 & 25.05 & & \\
\hline Total & 255937.97 & 10 & & & \\
\hline \multicolumn{6}{|c|}{ TPC-FBBB } \\
\hline Regressions & 1784276.48 & 5 & 356855.29 & 4.44 & 0.06355 \\
\hline Residues & 401112.48 & 5 & 80222.49 & & \\
\hline Lack of fit & 397305.73 & 3 & 132435.25 & 69.6 & 0.01420 \\
\hline Pure Error & 3806.74 & 2 & 1903.37 & & \\
\hline Total & 2185388.96 & 10 & & & \\
\hline \multicolumn{6}{|c|}{ Flavonoids } \\
\hline Regression & 874.57 & 5 & 174.91 & 9.43 & $0.01389 *$ \\
\hline Residues & 92.71 & 5 & 18.54 & & \\
\hline Lack of fit & 64.18 & 3 & 21.39 & 1.49 & 0.42403 \\
\hline Pure Error & 28.53 & 2 & 14.26 & & \\
\hline Total & 967.29 & 10 & & & \\
\hline \multicolumn{6}{|c|}{ DPPH } \\
\hline Regression & 175516.23 & 5 & 35103.24 & 2.73 & 0.14716 \\
\hline Residues & 64269.43 & 5 & 12853.88 & & \\
\hline Lack of fit & 64269.21 & 3 & 21423.07 & 194427.51 & 0.000005 \\
\hline Pure Error & 0.22 & 2 & 0.11 & & \\
\hline Total & 239785.66 & 10 & & & \\
\hline \multicolumn{6}{|c|}{ FRAP } \\
\hline Regression & 2015.92 & 5 & 403.18 & 1.05 & 0.476405 \\
\hline Residues & 1906.84 & 5 & 381.36 & & \\
\hline Lack of fit & 1906.72 & 3 & 635.57 & 10575.24 & 0.00009 \\
\hline Pure Error & 0.12 & 2 & 0.06 & & \\
\hline Total & 3922.77 & 10 & & & \\
\hline \multicolumn{6}{|c|}{ ABTS } \\
\hline Regression & 1152.46 & 5 & 230.49 & 10.34 & $0.01137^{*}$ \\
\hline Residues & 111.43 & 5 & 22.28 & & \\
\hline Lack of fit & 100.14 & 3 & 33.38 & 5.91 & 0.14807 \\
\hline Pure Error & 11.29 & 2 & 5.64 & & \\
\hline Total & 1263.89 & 10 & & & \\
\hline 2,2-diphenyl & he $5 \%$ level $(p<0$ & $\begin{array}{l}\text { ABTS = } \\
\text { cid) radic } \\
6-T r i s(2-n)\end{array}$ & $\begin{array}{l}\text { antioxidant acti } \\
\text { al; FRAP = ant } \\
\text { vridll-s-traze }\end{array}$ & 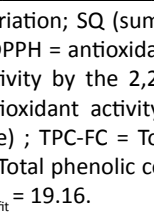 & '-azino-b \\
\hline
\end{tabular}

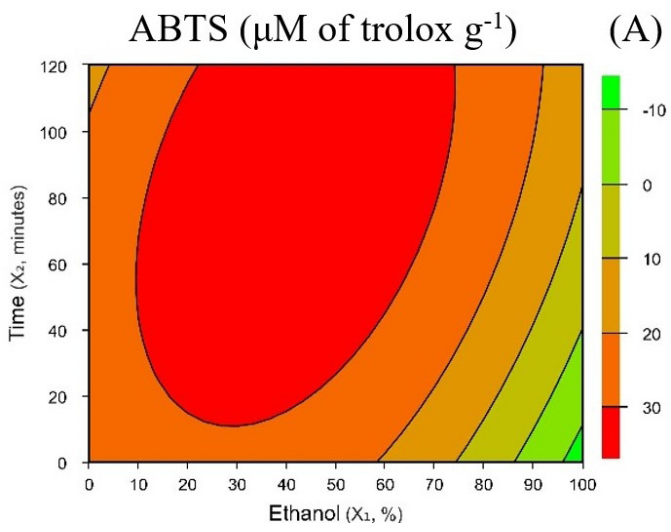

Table 6. Analysis of the Effects from the response variables Flavonoids and ABTS.

\begin{tabular}{ccccc}
\hline \multirow{2}{*}{$\begin{array}{c}\text { Coefficient } \\
\text { of regression }\end{array}$} & \multicolumn{2}{c}{ FT } & \multicolumn{2}{c}{ ABTS } \\
\cline { 2 - 5 } & Coeff. & p-Value & Coeff. & p-Value \\
\hline$\beta_{0}$ & 46.62 & $0.000007^{*}$ & 35 & $0.0001^{*}$ \\
$\beta_{1} x_{1}$ & -6.33 & $0.008^{*}$ & -7.01 & $0.0085^{*}$ \\
$\beta_{2} \mathrm{x}_{1}{ }^{2}$ & -8.61 & $0.005^{*}$ & -9.92 & $0.0041^{*}$ \\
$\beta_{3} \mathrm{x}_{2}$ & 3.02 & 0.10 & 4.10 & 0.0574 \\
$\beta_{4} \mathrm{x}_{2}{ }^{2}$ & 0.59 & 0.75 & -2.69 & 0.2328 \\
$\beta_{5} \mathrm{x}_{1} \mathrm{x}_{2}$ & -0.54 & 0.81 & 4.13 & 0.1403 \\
$\mathrm{R}^{2}$ & \multicolumn{2}{c}{$90.41 \%$} & \multicolumn{2}{c}{$91.18 \%$} \\
\hline
\end{tabular}

*Significantly different at the $5 \%$ level $(p<0.05)$. In which: ABTS: antioxidant activity by the 2,2'-azino-bis(3-ethylbenzothiazoline-6-sulfonic acid) radical; FT: Total Flavonoids; Coeff.: Coefficient; $\mathrm{R}^{2}$ : Coefficient of determination $\mathrm{x}_{1}$ : ethanol concentration; $\mathrm{x}_{2}$ : ultrasound-assisted extraction time.

phenolic compounds extracting from pitaya peel with solvent of different ethanol concentrations, the best results were concentrated in the range from 10 to $40 \%$ of ethanol.

As for the antioxidant activity by the ABTS method, the optimal extraction region is comprised between 9 and $73 \%$ of ethanol as solvent and between 10 and 120 minutes of extraction in an ultrasonic bath.

As seen on Figure $1 \mathrm{~B}$, the time for obtaining an extract with high antioxidant activity is above 24 minutes of extraction by ultrasonic bath. The need for a longer time can be explained by the pectin concentration in the pitaya peel, hindering the bioactive compounds diffusion for the solvent, thus requiring more time for extraction (Ramli et al., 2014). According to Ferreres et al. (2017), in a study on optimizing the phenolic compounds extraction from pitaya peel, they observed a difference between the times of 5 and 65 minutes and an equality in the temperature variation, where the 65 -minutes time was the best result found. This result is in agreement with the previous trial, which was performed with the total flavonoids present in this present study.

\section{Correlation among the response variables}

In principal component analysis (PCA), the angle among the variables is an indicative of the existence or not of their correlation in the experiment (Figure 2). Therefore, when comparing two variables, it is necessary identifying if the smallest angle formed (between $0^{\circ}$ and $180^{\circ}$ degrees) of

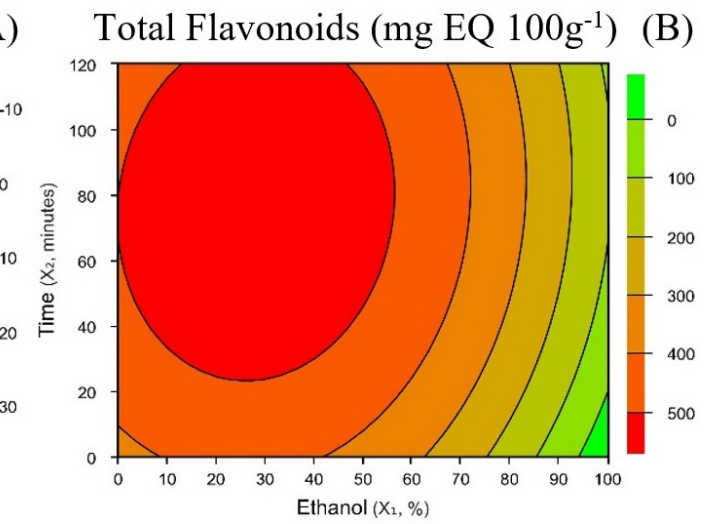

Figure 1 . Response surface for antioxidant activity by the method of ABTS (A) and total flavonoids (B) in extraction with proportion variables of ethanol as solvent and extraction time in an ultrasonic bath on the pitaya peel flour. 
this correlation is inferred, as the coefficient is calculated by the cosine of this value. If it is close to zero degrees $\left(0^{\circ}\right)$, the $r$ correlation coefficient is close to 1 , indicating a strong and positive correlation between the variables; if the angle is close to one hundred and eighty degrees (180),$r$ is close to -1 , indicating a strong negative correlation between the variables; and if the angle is close to ninety degrees (90\%), the correlation is either weak or nonexistent.

According to Figure 2, thee is a strong negative correlation between DPPH and FRAP, indicating that the decrease in the DPPH values occurs in line with the increase in FRAP. This behavior is explained by both being analyzes of the antioxidant activity; however, the DPPH value is inversely proportional to the antiradical activity, since the lower the concentration of test substance necessary to reach $\mathrm{EC}_{50}$ is, the greater the antiradical potential of this substance will be.

There is a strong positive correlation between ABTS and TPC-FC, where the behavior of these two variables is very close. The increasing ABTS value is expected with the higher content of phenolic compounds in an extract. Proestos et al. (2006) observed in their studies that the antioxidant activity of plant extracts is dependent on the total phenolic content of the species.

Phenolic compounds are antioxidants from the chainterminating type (Tikhonov et al., 2008; Kancheva, 2009). These antioxidants have the ability in donating a hydrogen atom to a free radical much more rapidly than how a free radical reacts with its substrate, thus stabilizing the free radical (Ou et al., 2001).

TPC-FBBB and FRAP variables also have a strong positive correlation, since an acute angle occurs between them.
Thaipong et al. (2006) concluded, in their study with guava extract, that the FRAP technique had high reproducibility, having the greatest correlation with the total phenolic content.

It is also possible to identify that the Total Flavonoids and TPC-FBBB do not show correlation; hence, we can state that the behavior of one of these is not a measurement parameter for the other. This can be explained the dependence of the antioxidant activity of phenolic compounds on their structure.

The efficiency of phenolic compounds, as antioxidants, depends on factors such as the number of hydroxyls linked to the aromatic ring and the binding site to the position of these hydroxyls in relation to each other (Sroka \& Cisowski, 2003). For example, Rice-Evans et al. (1996) describe that the presence of hydroxyls in the ortho position in the aromatic ring of phenolic compounds increases its capacity with antioxidant.

In studies on the antioxidant activity of acids such as the gallic, caffeic, protocatechuic, gentisic and chlorogenic, among others, the gallic acid had the greatest antioxidant potential (Sroka \& Cisowski, 2003). These researchers affirm that the high antioxidant activities found for 1,2,3-Trihydroxybenzene and gallic acid are related to the three hydroxyl groups linked to the ring in the position ortho one in relation to the others, and conclude that the number and position of hydroxyls in the benzene ring are the main factor that justifies the antioxidant activity in phenolic acids. Hence, in some cases, the antioxidant activity is related to the presence of phenolic acids, which are detected in quantification tests for total phenolics, but not in quantification tests for total flavonoids.

Still within the PCA (Figure 2), it is possible to identify which treatments may be contributing for each response, with

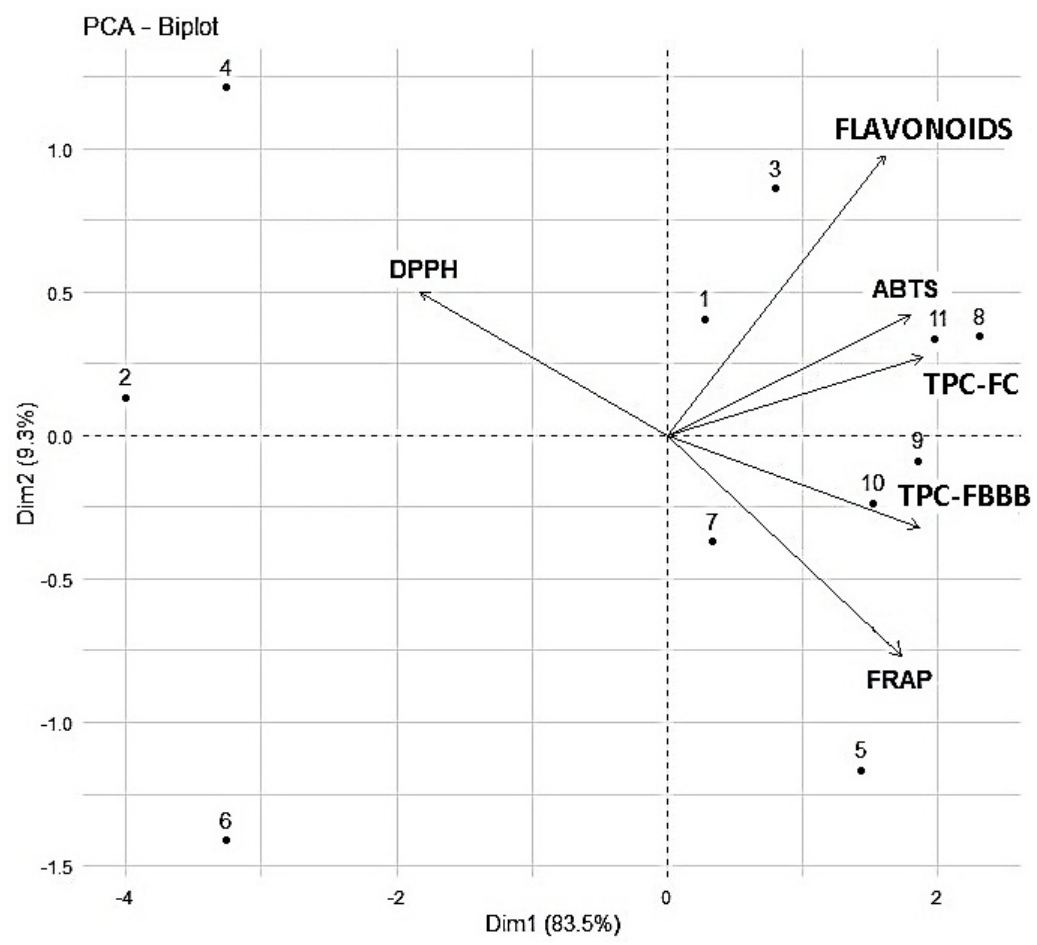

Figure 2 . Principal component analysis of the independent variables and responses to the extraction optimization of total phenolic compounds, flavonoids and antioxidant activity from pitaya peel flour. 
Table 7. Pearson correlation coefficient among the response variables of the extraction optimization of the pitaya peel flour.

\begin{tabular}{|c|c|c|c|c|c|}
\hline & TPC-FBBB & FRAP & Flavonoids & TPC-FC & ABTS \\
\hline TPC-FC & - & - & - & - & 0.93 \\
\hline Flavonoids & - & - & - & 0.82 & 0.79 \\
\hline FRAP & - & - & 0.55 & 0.77 & 0.76 \\
\hline DPPH & -0.93 & -0.90 & -0.69 & -0.85 & -0.73 \\
\hline
\end{tabular}

In which: DPPH = antioxidant activity by the 2,2-diphenyl-1-picrylhydrazyl radical; ABTS = antioxidant activity by the 2,2'-azino-bis(3-ethylbenzothiazoline-6-sulfonic acid) radical; FRAP $=$ antioxidant activity in reducing the Fe(III) by the TPTZ complex (2,4,6-Tris(2-pyridyl)-s-triazine) ; TPC-FC= Total phenolic compounds by the Folin-Ciocauteau method; TPC-FBBB = Total phenolic compounds by the Fast Blue BB method.

this seen by the proximity and direction in the figure. DPPH is the answer that is favored by treatments 2 and 4 , which have in common the ethanol concentration of $85.35 \%$. Total flavonoids are favored in treatments 1 and 3 , which have in common the ethanol concentration of $14.65 \%$. The ABTS and TPC-FC variables are favored by treatments 11 and 8 , which have in common the ethanol concentration of $50 \%$. Whereas the TPC-FBBB has favorable conditions for treatment 10 and FRAP for treatment 7.

According to the principal component analysis, Pearson test was performed among the optimization response variables, with Table 7 displaying these results.

There is no consensus in the literature regarding the values from Pearson correlation and their intensity. For Cohen (1988), values between 0.10 and 0.29 indicate a small correlation; with those between 0.30 and 0.49 considered as medium; and values between 0.50 and 1 able to be be interpreted as a strong correlation. For Dancey \& Reidy (2005) though, values between 0.10 to 0.30 indicate a weak correlation; between 0.40 and 0.60 a moderate correlation; and between 0.70 and 1 indicate a strong correlation. Crespo (2002) determines that the range between 0 and 0.3 indicates a very weak correlation; while between 0.3 and 0.6 indicates a relatively weak correlation; and values between 0.6 and 1 allow the significant conclusions about the correlation.

By using Dancey \& Reidy (2005) as reference, on the analysis of total phenolic compounds, it is verified that the correlations with the analysis of antioxidant activity were deemed as strong.

The total flavonoids present in the analyzed extracts have a moderate correlation with the FRAP (0.55) and DPPH (-0.69) tests and a strong correlation with the ABTS test (0.79). The strong correlation between the TPC-FC method and the flavonoid quantification method (0.82) can be explained by underestimating the phenolic quantification method, since its correlation was moderate in relation to the one from the TPCFBBB method.

The correlation between ABTS and DPPH (-0.73) corresponds to the lowest among the presented antioxidant activity methods. This is due to the chemical complexity of the compounds in the extracts, the functional groups and the chemical behavior that may lead to contradictory results and the different forms that antioxidants have with different radicals, where the ABTS method has a greater capacity in evaluating lipophilic and hydrophilic compounds, while DPPH has solubility problems and may have lower values (Morzelle,
2016). Regarding DPPH and FRAP, there is a strong correlation between these methods $(-0.90)$, with a result similar to what was found by Fathordoobady et al. (2016), in a study of extracting compounds from pitaya peel and pulp by different methods, where the methods had a correlation of 0.97 .

\section{Conclusion}

Pitaya peel flour has a high concentration of phenolic compounds with high antioxidant activity.

The optimal extraction of flavonoid compounds, where the extract shows greater antioxidant activity by the ABTS method, is comprised between 13 and $57 \%$ of ethanol as a solvent and with time above 86 minutes of extraction in an ultrasonic bath.

Pitaya peel flour is thus presented as a promising antioxidant additive for use in food products.

\section{Literature Cited}

Aliakbarlu, J.; Ghiasi, S.; Bazargani-Gilani, B.Effect of extraction confitions on antioxidante activity of barberry (Berberis vulgaris L.) fruit extracts. Veterinary Research Forum, v.9, n.4, p. 361-365, 2018. https://doi.org/10.30466/vrf.2018.33090.

Alves, A. C. B.; Monteiro, L. B.; Pompeu, D. R. Otimização da extração sólido-líquido de compostos fenólicos totais e betalaínas da casca de frutos de pitaya (Hylocereus polyrhizus). Revista Brasileira de Tecnologia Agroindustrial, v. 12, n. 1, p. 2556-2577, 2018. https:// doi.org/10.3895/rbta.v12n1.4668.

Arnao, M.B. Some methodological problems in the determination of antioxidant activity using chromogen radicals: a practical case. Trends in Food Science \& Technology, v.11, n.11, p.419-421, 2000. https://doi.org/10.1016/S0924-2244(01)00027-9.

Aware, C. B.; Ravishankan, R. P.; Vyavahare, G. D.; Gurme, S. T.; Jadhav, J. P. Ultrasound-assisted aqueous extraction of phenolic, flavonoid compounds and antioxidant activity of Mucuna macrocarpa beans: response surface methodology optimization. Journal of the American College of Nutrition, v.38, n.4, p.364372, 2018. https://doi.org/10.1080/07315724.2018.1524315.

Cassol, L. A.; Filho, E. S. A.; Oliveira, A. C. S. Performace comparision between a natural and comercial antioxidante on smoked pacu (Piaractus mesopotamicus). Journal of Agricultural Science, v. 11, n. 2, p.225-235, 2019. https://doi.org/10.5539/jas.v11n2p225.

Cohen, Jacob. Statistical power analysis for the behavioral sciences. 2.ed. New York: Lawrence Erlbaum Associates, 1988. 579 p.

Crespo, A. A. Estatística fácil. 17.ed. São Paulo: Saraiva, 2002. 224 p. 
Dancey, C.; Reidy, J. Estatística sem matemática para Psicologia: usando SPSS para Windows. 3.ed. Porto Alegre: Artmed, 2006. $608 p$.

Duthie, G. G.; Duthie, S. J.; Kyle, J. A. M. Plant polyphenols in cancer and heart disease implications as nutritional antioxidants. Nutrition Research Reviews, v. 13, n.1, p. 79-106, 2000. https:// doi.org/10.1079/095442200108729016.

Fathordoobady, F.; Mirhosseini, H.; Selamat, J.; Manap, M. Y. A. Effect of solvent type and ratio on betacyanins and antioxidant activity of extracts from Hylocereus polyrhirus flesh and peel by supercritical fluid extraction and solvent extraction. Food Chemistry, v. 202, n. 1, p. 70-80, 2016. https://doi.org/10.1016/j. foodchem.2016.01.121.

Ferreres, F.; Grosso, C.; Gil-Izquierdo, A.; Valentão, P.; Mota, A. T.; Andrade, P. B. Optimization of the recovery of high-value compounds from pitaya fruit by-products using microwaveassisted extraction. Food Chemistry, v. 230, p. 463-474, 2017. https://doi.org/10.1016/j.foodchem.2017.03.061.

Fetni, S.; Bertalla, N.; Ouahab, A. Zapater, J. M. M.; Fernandez, S. P. Composition and biological activity of the Algerian plant Rosa canina L. by HPLC-UV-MS. Arabian Journal of Chemistry, v.13, n.1, p.1105-1119, 2017. https://doi.org/10.1016/j. arabjc.2017.09.013.

Granato, D.; Santos, J. S.; Maciel, L. G.; Nunes, D. S. Chemical perspective and criticism on selected analytical methods used to estimate the total content of phenolic compounds in food matrices. TrAC Trends in Analytical Chemistry, v. 80, p. 266-279, 2016. https://doi.org/doi: 10.1016/j.trac.2016.03.010.

Hua, Q.; Zhou, Q.; Gan, S. Wu, J., Chen, C.; Li, J.; Ye, Y.; Zhao, J.; Hu, G.; Qin, Y. Proteomic analysis of Hylocereus polyrhizus reveals metabolic pathway changes. International Journal of Molecular Sciences, v.17, n.10, e1606, 2016. https://doi.org/10.3390/ ijms17101606.

Jeronimo, M. C. Caracterização química, física, atividade antioxidante e avaliação dos efeitos citotóxicos da pitaya-vermelha [Hylocereus undatus (haw) Britton \& Rose] cultivada no Brasil. Universidade de Brasília. Brasília-DF, 2016. 56 p. Dissertação Mestrado. https:// repositorio.unb.br/handle/10482/22448. 29 Mar. 2019.

Jurd, L.; Geissman, A. Absorption spectra of metal complexes of flavonoid compounds. Journal of Organic Chemistry, v. 21, n. 2, p. 1395 - 1402, 1956. https://doi.org/10.1021/jo01118a018.

Kancheva, V. D. Phenolic antioxidants - radical-scavenging and chainbreaking activity: a comparative study. European Journal of Lipid Science and Technology, v. 111, n. 11, p. 1072-1089, 2009. https://doi.org/10.1002/ejlt.200900005.

Kang, J.; Thakali, K. M.; Xie, C.; Kondo, M.; Tong, Y.; Ou, B.; Jensen, G.; Medina, M. B.; Schauss, A. G.; Wu, X. Bioactivities of acai (Euterpe precatoria mart.) fruit pulp, superior antioxidant and anti-inflammatory properties to Euterpe oleracea Mart. Food Chemistry, v. 133, n.3, p. 671-677, 2012. https://doi. org/10.1016/j.foodchem.2012.01.048.

Lang, G. H. H.; Silva, I.; Ferreira, C. D.; Hoffmann, J. F.; Vanier, N. L.; Oliveira, M. Effects of drying temperature and long-term sorage conditions on black rice phenolic compounds. Food Chemistry, v.287, p.197-204, 2019. https://doi.org/10.1016/j. foodchem.2019.02.028.
Leong, H. Y.; Ooi, C. W.; Law, C. L.; Julkifle, A. L.; Katsuda, T.; Show, P. L. Integration process for betacyanins extraction from peel and flesh of Hylocereus polyrhizus using liquid biphasic electric flotation system and antioxidant activity evaluation. Separation and Purification Technology, v. 209, p. 193-201, 2019. https://doi. org/10.1016/j.seppur.2018.07.040.

Lester, G. E.; Lewers, K. S.; Medina, M. B.; Saftner, R. A. Comparative analisys of strawberry total phenolic via Fast Blue BB vs. FolinCiocalteu: Assay interference by asxorbic acid. Journal of Food Composition and Analysis, v. 27, n.1, p. 102-107, 2012. http:// dx.doi.org/10.1016/j.jfca.2012.05.003.

Liu, F. F.; Ang, C. Y. W.; Springer, D. Optimization of extraction conditions for active components in Hypericum perforatum using response surface methodology. Journal Agricultural Food Chemistry, v. 48, n. 8, p. 3364-3371, 2000. https://doi.org/10.1021/jf991086m.

Medina, M. B. Simple and rapid method for the analysis of phenolic compounds in beverades and grains. Agricultural and Food Chemistry, v. 59, n.5, p. 1565-1571, 2011. dx.doi.org/10.1021/ jf103711c.

Mehta, D.; Sharma, N.; Bansal, V.; Sangwan, R. S.; Yadav, S. K. Impact of ultrasonication, ultraviolet and atmospheric cold plasma processing on quality parameters of tomato-based beverage in comparison with thermal processing. Innovative Food Science \& Emerging Technologies, v. 52, p. 343-349, 2019. https://doi. org/10.1016/j.ifset.2019.01.015.

Moreira S. A.; Alexandre, E. M. C.; Pintado, M.; Saraiva, J. A. Effect of emergent non-thermal extraction Technologies on bioactive individual compounds profile from different plant materials. Food Reseach International, v. 115, p. 177-190, 2018. https://doi. org/10.1016/j.foodres.2018.08.046.

Morzelle, M. C. Efeito neuroprotetor da casca de romã (Punica granatum). Piracicaba: Universidade de São Paulo; ESALQ, 2016. 125p. Tese Doutorado.

Ou, B.; Hampsch-Woodill, M.; Prior, R. L. Development and validation of an improved oxygen radical absorbance capacity assay using fluorescein as the fluorescent probe. Journal of Agricultural and Food Chemistry, v. 49, n. 10, p. 4619-4626, 2001. https://doi. org/10.1021/jf010586o.

Ozkan, G.; Kamiloglu, S.; Ozdai, T.; Boyacioglu, D.; Capanoglu, E. Potential use of turkish medicinal plants in the treatment of various diseases. Molecules, v. 21, n. 3, p. 257-289. 2016. https:// doi.org/10.3390/molecules21030257.

Paepe, D. D.; Valkenborg, D.; Coudijzer, K.; Noten, B.; Servaes, K.; Loose, M.; Voorspoels, L.; Diels, L.; Droogenbroeck, B. V. Thermal degradation of cloudy apple juice phenolic constituents. Food Chemistry, v. 162, p. 176-185, 2014. https://doi.org/10.1016/j. foodchem.2014.04.005.

Proestos, C.; Boziaris, I.S.; Nychas, G.-J.E.; Komaitis, M. Analysis of flavonoids and phenolic acids in Greek aromatic plants: Investigation of their antioxidant capacity and antimicrobial activity. Food Chemistry, v. 95, n. 4, p. 664-671, 2006. https://doi. org/10.1016/j.foodchem.2005.01.049.

Pulido, R.; Bravo, L.; Saura-Calixto, F. Antioxidant activity of dietary as determined by a modified ferric reducing/antioxidant power assay. Journal Agriculture and Food Chemistry, v. 48, n.8, p. 33963402, 2000. https://doi.org/10.1021/jf9913458. 
Ramli, N. S.; Ismail, P.; Rahmat, A. Influence of conventional and ultrasonic-assisted extraction on phenolic contents, betacyanin contents and antioxidant capacity of red dragon fruit (Hylocereus polyrhizus). The Scientific World Journal, v.2014, Article 964731, 2014. https://doi.org/10.1155/2014/964731.

Rice-Evans, C.; Miller, N. J.; Paganga, G. Structure-antioxidant activity relationships of flavonoids and phenolic acids. Free Radical Biology and Medicine, v. 20, n. 7, p. 933-956, 1996. https://doi. org/10.1016/0891-5849(95)02227-9.

Rodrigues, S.; Silva, E. O.; Brito, E. S. (Eds.). Exotic fruits reference guide. 1.ed. London: Academic Press, 2018. 488p.

Rodrigues, M. I.; Lemma, A. F. Planejamento experimental e otimização de processo. Campinas: AMIC Cárita., 2014. 618 p.

Rufino, M.; Alves, R. E.; Brito, E. S.; Pérez-Jimenez, J.; Saura-Calixto, F.; Mancini-Filho, J. Bioactive compounds and antioxidant capacities of 18 non-traditional tropical fruits from Brazil. Food Chemistry, v.121, n.4, p. 996-1.002, 2010. https://doi.org/10.1016/j. foodchem.2010.01.037.

Sroka, Z.; Cisowski, W. Hydrogen peroxide scavenging, antioxidant and anti-radical activity of some phenolic acids. Food and Chemistry Toxicology, v. 41, n. 6, p. 753-758, 2003. https://doi. org/10.1016/S0278-6915(02)00329-0.
Thaipong, K.; Boonprakob, U.; Crosby, K; Cisneroszevallos, L.; Byrne, D.H. Comparison of ABTS, DPPH, FRAP and ORAC assays for estimating antioxidant activity from guava fruit extracts. Journal of Food Composition and Analysis, v.19, n.6-7, p.669-675, 2006. https://doi.org/10.1016/j.jfca.2006.01.003.

Tikhonov, I.; Roginsky, V.; Pliss, E. The chain-breaking antioxidant activity of phenolic compounds with different numbers of $\mathrm{O}-\mathrm{H}$ groups as determined during the oxidation of styrene. International Journal of Chemical Kinetics, v. 41, n. 2, p. 92-100, 2008. https://doi.org/10.1002/kin.20377.

Woisky, R. G. Salatino, A. Analysis of propolis: some parameters and procedures for chemical quality control. Journal of Apicultural Research, v. 37, n.2, p. 99-105, 1998. https://doi.org/10.1080/00 218839.1998.11100961.

Wu, L.; Hsu, H.; Chen, Y.; Chiu, C.; Lin, Y.; Ho, J. A. Antioxidant and antiproliferative activities of res pitaya. Food Chemistry, v. 95, n.2, p. 319-327, 2006. https://doi.org/10.1016/j. foodchem.2005.01.002.

$\mathrm{Xu}, \mathrm{C}$;; Wang, B.; Pu, Y.; Tao, J.; Zhang, T. Advances in extraction and analysis of phenolic compounds from plant materials. Chinese Journal of Natural Medicines, v. 15, n. 10, p. 721-731, 2017. https://doi.org/10.1016/S1875-5364(17)30103-6. 